\title{
Tratamiento Cognitivo Conductual del Trastorno por Estrés Postraumático en un Caso de una Adolescente Víctima de Agresión Sexual
}

\section{Cognitive Behavioral Treatment of Post-Traumatic Stress disorder in a Case of a Teenage Victim of Sexual Assault}

\author{
Patricia Villavicencio Carrillo \\ Universidad Complutense de Madrid, España
}

\author{
Teresa Montalvo Calahorra \\ Hospital Clínico San Carlos de Madrid, España
}

Resumen. La violencia contra las mujeres y en especial las agresiones sexuales continúan siendo una verdadera lacra en nuestra sociedad. Se expone el tratamiento de una joven con TEPT asociado a una violación reciente por parte de un familiar; quien había agredido sexualmente a la joven cuando tenía 14 años en su país de origen. Se completa una Terapia Cognitivo-Conductual en la que se aplica la técnica de exposición a los síntomas principales como imágenes intrusivas y pesadillas relacionadas con la agresión sexual reciente, relajación muscular progresiva, y sesiones familiares de psicoeducación con relación a los síntomas de TEPT. Tras 27 sesiones individuales y 8 grupales a lo largo de 12 meses se consigue un éxito terapéutico completo.

Palabras Clave: violencia contra las mujeres, agresión sexual, estrés post traumático, abuso intrafamiliar, reestructuración cognitiva.

Abstract. Violence against women, especially sexual violence continues to be a real scourge in our society. We describe the treatment of a 19 year old with PTSD after of being raped by a close relative, who had sexually assaulted the girl when she was 14 years old in their country of origin. After one year of Cognitive-Behavioral treatment (prolonged exposure, cognitive restructuring, anxiety management training and family psycho education regarding posttraumatic symptoms and suicidal ideation) the patient shows full recovery of the posttraumatic symptoms and therapeutic success.

Keywords: violence against women, sexual violence, post traumatic stress disorder, infamily abuse, congnitive restructuring.

\section{Introducción}

La violencia contra las mujeres y en especial las agresiones sexuales continúan siendo una verdadera lacra en nuestra sociedad. Muchas mujeres y niñas en el mundo son sometidas sistemáticamente a la violencia, a la tortura, coerción, abuso sexual, hambre y privación económica. La violencia contra las mujeres y las niñas es la violación de los derechos humanos más extendida de nuestro tiempo.

La correspondencia sobre este artículo puede dirigirse a la autora al E-mail: patriciavillavicencio@gmail.com 
A pesar de que existen diferentes tipos de violencia contra las mujeres, todas comparten ciertas características. Por ejemplo, la violencia dentro de la pareja, el abuso sexual en la infancia y los abusos sexuales cometidos por conocidos suelen perdurar en el tiempo, llegando incluso a décadas. A menudo la victima no solo conoce a su agresor antes del primer incidente, sino que puede que viva con él o interactúe regularmente con él.

En la mayoría de los estudios, las niñas tienen entre 1.5 a 3 veces mas probabilidad de sufrir abusos sexuales que los niños. Por otro lado, las Naciones Unidas (2006) estima que una de cada cinco mujeres será víctima de violación o intento de violación en su vida. Otro dato alarmante es que en estos estudios parte de las adolescentes manifiesten haber sufrido una iniciación sexual forzada.

En cuanto a la incidencia de esta problemática en el ámbito español, el Ministerio del Interior, en el año 2009 registró 6.573 delitos contra la libertad y la identidad sexual. En la Comunidad de Madrid en ese mismo año se registraron un total de 1340 denuncias; estas cifras han sufrido un incremento considerable con relación a las registradas en el año 1999 que se denunciaron solo 837. Estas cifras serían la punta del iceberg, dado que solamente un pequeño porcentaje de víctimas se atreve a denunciar ya sea por vergüenza, o en caso de ser un conocido por miedo a la violencia que podría suscitar en su agresor (Villavicencio, Bustelo y Valiente, 2007).

Con relación a los costes en la Salud Pública encontramos que en el informe Mundial sobre la violencia y la salud de la OMS (2002) se resalta que la violencia supone una carga enorme para las economías nacionales además del sufrimiento humano en las víctimas. Se expone que las víctimas de agresiones sexuales presentan más problemas de salud, generan costos de atención sanitaria significativamente más elevados y acuden con mayor frecuencia a los servicios hospitalarios de urgencia que las personas que no han sufrido este tipo de abusos.

Las consecuencias físicas de la violación y de los abusos sexuales posiblemente explicarían la alta prevalencia de problemas ginecológicos, embarazos no deseados, enfermedades de transmisión sexual, VIH, SIDA, infecciones urinarias, problemas digestivos, pérdida de apetito, síndrome del colon irritable, fibromialgia, etc. En definitiva, estas víctimas suelen presentar un pobre estado de salud física general.

Respecto a las consecuencias psicológicas, Amor, Echeburua, de Corral, Zubizarreta, y Sarasua, (2001) encontraron que la tasa de prevalencia del trastorno de estrés postraumático en víctimas de violencia familiar sin agresiones sexuales (42\%) aumenta considerablemente (54\%) cuando hay relaciones sexuales forzadas. En este estudio se señala que el mero paso del tiempo no es una condición suficiente, al menos en una mayoría de las víctimas, para que desaparezcan los síntomas del trastorno. Anteriormente, este mismo grupo de investigadores observaron que las víctimas de agresiones sexuales presentaban entre un 50\% e incluso un $70 \%$ un trastorno por estrés postraumático agudo y/o crónico (Echeburúa; Corral, Saraús y Zubizarreta, 1995). Este tipo de población presenta un alto riesgo de sufrir este trastorno y por ende exige la puesta a punto de programas de intervención eficaces. El diagnóstico de Trastorno de Estrés Postraumático (TEPT) se ha convertido en la actualidad en uno de los más utilizados con víctimas de agresiones sexuales.

El TEPT describe un patrón de síntomas que puede desarrollarse en individuos que han sufrido estímulos estresantes traumáticos. En 1978, Charles Figley publicó el primer libro de esta nueva era del estudio del Trauma: Stress disorders among Vietnam Veterans, en el que se delinea las características principales de lo que luego se conocería como trastorno por estrés postraumático. Apoyado por el movimiento pacifista, esta vez el estudio de las secuelas traumáticas de la guerra llegó a conseguir el reconocimiento oficial de la existencia de un trastorno debido a los hechos traumáticos. En 1980, la Asociación Norteamericana de Psiquiatría introduce en el DSM-III el diagnóstico de Trastorno por Estrés Postraumático. El movimiento feminista a partir de los años 70 hizo visible que las víctimas de la violencia sexual y doméstica presentaban síntomas similares a los de los veteranos de guerra (Herman, 2004).

Van der Kolk; Roth; Pelcovitz, Sunday, y Spinazzola (2005) subrayan que los niños y los adultos que han sido expuestos a un trauma interpersonal crónico y prolongado presentan sintomatología psicológica que no se refleja en el TEPT y manifiestan problemas con: (a) la regulación de las emociones y los impulsos (b) memoria y atención, (c) auto-percepción, (d) relaciones interpersonales e) somatización, y (f) sistemas de creencias. Estos datos resaltarían cuestiones relacionadas con la categoría y la naturaleza dimensional del Trastorno por 
Estrés Postraumático, así como también la comorbilidad de otros trastornos. En los últimos años se ha producido un gran interés sobre cómo el trauma puede precipitar o favorecer la aparición de cuadros psicóticos y se plantea, que tanto la psicosis como el TEPT, representan un continuo de respuestas ante los eventos traumáticos (Morrison, Frame y Larkin; 2003; Valiente, Villavicencio y Cantero, 2006).

Recientemente, Kelly, Weathers, Meghan, McDevitt-Murphy, Eakin y Flood (2009) señalan que a pesar de que se asuma que el TEPT es un síndrome equivalente a pesar del tipo de trauma experimentado, en el DSMIV-TR y en las investigación se observa que los distintos tipos de trauma provocan variantes en el TEPT, y en especial las agresiones sexuales frente a los accidentes de tráfico y la pérdida de un ser querido, eran un predictor de gravedad del trastorno. Esto les sugiere que cierto tipo de eventos traumáticos, en especial las agresiones sexuales están asociados no sólo con un alto riesgo de padecer un TEPT sino también de presentar una sintomatología más elevada y grave del trastorno. También observaron que este tipo víctimas de trauma presentaban una respuesta de miedo más elevada y cambios en las estructuras cognitivas relacionadas con lo social, por lo que proponen que estos resultados se tomen en consideración para futuras investigaciones y propuestas de tratamiento. Echeburúa y Corral (1997) consideran que este perfil diferencial se debe principalmente a que las víctimas de agresiones sexuales sufren este tipo de acontecimiento con frecuencia en un ambiente supuestamente seguro en el que se desenvuelven en su vida normal.

En el estudio de Darves-Herman, Bornoz y col. (2008), sobre la epidemiología de las enfermedades mentales en Europa (Bélgica, Francia, Holanda, Italia, España, y Alemania), aparecieron una gran variedad de eventos traumáticos (aprox. 28) relacionados con la aparición del TEPT entre los que se encontraban: las guerras/conflictos bélicos o regiones en conflicto, secuestro, tortura, sufrir o ver atrocidades, accidentes, desastres naturales, maltrato físico y sexual, violación, acoso, muerte repentina de un ser querido, tener un hijo con una enfermedad grave, entre otros.

En definitiva, el trastorno de estrés postraumático se ha aplicado a un gran número de traumas, incluyendo víctimas de delitos, víctimas de violación, abuso sexual infantil, abuso físico, incluyendo maltrato doméstico (Walker, 2009), víctimas de accidentes de tráfico, víctimas de tortura y víctimas de desastres tanto naturales como provocados por el ser humano (Foa, Keane, Friedman, y Cohen, 2009). Se puede incluso señalar que es un diagnóstico que se ha «puesto de moda» en los últimos años, lo que por un lado ha aumentado el número de diagnósticos y por otro los esfuerzos para desarrollar procedimientos eficaces de intervención.

Según el Manual Diagnóstico y Estadístico de los Trastornos Mentales (DSM-IV-TR), el trastorno de estrés postraumático aparece cuando la persona ha sufrido, ha sido testigo o ha sabido por personas cercanas de la existencia de acontecimientos traumáticos, que representan una amenaza para su vida, su propia integridad física o de otra persona, y cuando la reacción emocional experimentada implica una respuesta intensa de temor, desesperanza u horror. Las víctimas reexperimentan el acontecimiento traumático en forma de recuerdos o sensaciones intrusivas (flashbacks o pesadillas), evitan situaciones o/y huyen de lugares y situaciones asociados al hecho traumático, incluso de pensamientos o sentimientos para distanciarse emocional y psicológicamente. Suele aparecer también un cierto embotamiento emocional, extrañeza, anhedonia, así como el señalamiento de que el acontecimiento ha marcado una ruptura vital. La ansiedad, es decir, un incremento en la activación fisiológica, manifestada en hipervigilancia, dificultades de concentración, irritabilidad y los episodios de ira, problemas para conciliar el sueño, son también comunes. Todos estos síntomas se agrupan en las siguientes categorías: reexperimentación, evitación/embotamiento y de hiperactivación. En ocasiones suele aparece amnesia disociativa, manifestada en una incapacidad para recordar la información relacionada con el hecho traumático. A esto se añaden sentimientos de vergüenza, culpabilidad, tendencia a olvidar, dificultades de procesamiento, etc. Es importante tener en consideración que existe un incremento del riesgo de desarrollar trastornos como la depresión, la ansiedad, ideas suicidas y abuso de sustancias psicoactivas (alcohol y otras sustancias de abuso). Dentro de un marco de atención integral los profesionales de la salud pública deben de conocer que es frecuente que las personas afectadas por este trastorno presenten síntomas físicos, tales como trastornos gastrointestinales, vértigo, dolores de cabeza. 
Todos estos síntomas deben experimentarse durante al menos un mes, con el fin de recibir el diagnóstico de TEPT. Un porcentaje importante de los que han sufrido un trauma muestra síntomas completos de TEPT inmediatamente después de sufrir el acontecimiento traumático. Sin embargo, este porcentaje se reduce casi a la mitad durante los tres meses que siguen al trauma, tendiendo entonces a estabilizarse. Por ejemplo, en el estudio llevado a cabo por Foa y Rothbaum (1991), cuando se evalúo a las dos semanas, al mes, a los tres meses, a los seis meses y a los nueve meses a personas que habían sufrido una violación, éstas manifestaron los síntomas de un TEPT, en un $94 \%$, un $65 \%$, un $47 \%$, un $42 \%$ y un $42 \%$ respectivamente. Así, después de los tres meses, los porcentajes de personas que manifestaban un TEPT no disminuyeron de forma substancial. Si los síntomas no remiten dentro de este periodo de tiempo, el TEPT suele persistir, incluso empeorar sin la intervención apropiada.

La prevalencia del TEPT es difícil de estimar, dado que se incluyen casos muy dispares y existen problemas en la identificación de cifras, dependientes éstas de la categorización e instrumentos de evaluación empleados, o de la presencia de sucesos traumáticos. Quizá por eso, se estima que su prevalencia oscila entre el $1 \%$ y el $14 \%$ en la población general. No obstante se considera como trabajo de referencia el de Kessler y cols. (1995) (se estudió a 5.877 personas; con edades entre 15-54 años), que señala una tasa del 8\% en adultos (10.4\% mujeres y $5 \%$ hombres). Presenta además una alta comorbilidad, estimando la presencia de al menos otro problema a la vez en un $88.3 \%$ de los hombres y $79 \%$ de las mujeres, además de que muchos de sus síntomas son similares a los de otros trastornos como depresión o ansiedad generalizada. Estos últimos pueden ser suficientemente graves como para merecer el diagnóstico de trastorno de ansiedad o depresión adicional (Walker, 1994).

Los síntomas suelen variar según el estadío de desarrollo y se señala que muchos de los criterios del TEPT pueden no ser lo adecuadamente sensibles para detectar el impacto de acontecimientos traumáticos en especial en niños en etapas tempranas de desarrollo (American Academy of Child and Adolescent Psychiatry, 1998). La intensidad de la exposición al trauma, la angustia relacionada con el trauma de los padres y la proximidad cronológica con el acontecimiento traumático son señaladas como variables predictoras (Foy, Madvig, Pynoos y Caillieri, 1994; Silverman, W. K., et al., 2008).

Los síntomas tienden a asemejarse a los de los adultos en el caso de la adolescencia (Cohen, Berliner y March, 2000). Brewin, Andrews y Valentine (2000) realizaron un meta-análisis sobre los factores riesgo del TEP en adultos y encontraron los siguientes factores riesgo: ser mujer, joven, la raza, estatus socioeconómico, bajo nivel intelectual, bajo nivel educativo, traumas previos, experiencias infantiles adversas, gravedad del trauma, falta de apoyo social, abuso infantil, problemas psiquiátricos e historia psiquiátrica familiar. Es necesario resaltar que se reconoce que el TEP es una categoría diagnostica inherentemente limitada y en especial con los supervivientes de abusos sexuales en etapas muy tempranas y malos tratos o violencia doméstica. Estas personas muestran problemas relacionales que aumentan su malestar e interfieren en su funcionamiento general. Existe un consenso clínico amplio y cierto grado de apoyo empírico que señala que este tipo de pacientes requieren intervenciones multimodales de larga duración (Foa, Keane, Friedman y Cohen, 2009). En cuanto a las tasas de prevalencia del TEPT en niños y adolescentes resulta muy difícil de valorar dado el poco interés que esto ha suscitado en el ámbito de investigación.

El TEPT tiende a cronificarse con el tiempo si no se recibe un tratamiento adecuado. Sin embargo, no todas las victimas que experimentan un trauma necesitan un tratamiento especializado. Aquellas que no recuperan la normalidad en sus constantes biológicas con respecto al sueño y al apetito, viven desbordas por el trauma y no se sienten capaces de conseguir un funcionamiento social, laboral y familiar adecuado necesitando de tratamiento psicológico especializado y en algunas ocasiones farmacológico (Echeburua, 2004). Desafortuna-damente, la mayoría de los pacientes con TEPT no recibe tratamientos consistentes con las directrices de consenso propuestas por los expertos (Echeburúa y Corral, 2007). Sin embargo, en estos últimos años podemos encontrar estudios en el ámbito internacional y nacional que pretenden analizar la eficacia de los tratamientos, principalmente en el campo del TEPT (Bisson y Cohen, 2006; Cloitre, 2009; Echeburúa, 2004). Frueh, Grubaugh, Cusack, y Elhai (2009) mencionan que en los EEUU muy pocos centros de salud mental públicos ofertan regularmente servicios especializados para el tratamiento de este trastorno. Dado que esta problemática presenta índices muy preocu- 
pantes tanto a nivel mundial como nacional obliga a los profesionales de la salud a tomar conciencia de la alta probabilidad de que lleguen a sus consultas mujeres y adolescentes con diversa sintomatología somática y psíquica que no revelen haber o estar padeciendo abusos o violencia sexual. Por esta razón, es necesario estar alertas ante los síntomas más comunes y especializarse en los tratamientos de evidencia empírica más eficaces.

Recientemente, respecto al tratamiento con niños y adolescentes expuestos a eventos traumáticos, Silverman y cols (2008) realizaron una revisión de la literatura y meta-análisis de 21 estudios de los tratamientos más rigurosos y encontraron que la terapia cognitivo-conductual enfocada al trauma eran los únicos tratamientos que cumplieron los criterios de eficaces, mientras que los grupos en la escuela basados en programas de tratamiento cognitivo-conductual se clasificaron como probablemente eficaces. Los resultados de los meta-análisis reveló tamaños moderados de efecto para el tipo de trauma, el tipo de intervención y participación de los padres. La terapia cognitivo-conductual enfocada al trauma está compuesta por técnicas de exposición, relajación y técnicas de control del estrés y reestructuración cognitiva.

En cuanto al tratamiento del TEP en adultos la Terapia Cognitivo Conductual (TCC) es la de mayor evidencia empírica. Esta afirmación está refrendada por la investigación y las principales guías de tratamiento basadas en la evidencia. Por ejemplo, el National Institute for Clinical Excellence (NICE) británico recomienda que la TCC sea el tratamiento de primera elección para el TEPT. El Informe de la división 12 de la APA (American Psychological Association) señala como tratamientos empíricamente validados los siguientes: la terapia de exposición prolongada, la terapia de procesamiento cognitivo y la terapia de reprocesamiento y desensibilización por movimientos oculares, siendo ésta última a pesar de mostrar una alta evidencia empírica señalada como controvertida.

A continuación presentaremos un breve resumen de los tratamientos psicológicos de alta validez empírica según la División 12 de la APA:

1. Terapia de procesamiento cognitivo para el Trastorno por Estrés Postraumático. La terapia de procesamiento cognitivo (TPC), está diseñada para desafiar y cambiar las creencias distorsionadas y el sentimiento de culpa provocados por el acontecimiento traumático a través del cuestionamiento socrático. La TPC también contiene un componente de exposición, a través de la escritura sobre el evento traumático; sin embargo, el objetivo principal de la terapia es modificar las creencias sobre el significado y las implicaciones del suceso traumático. (Monson, Schnurr, Resick, Friedman, Young-Xu, y Stevens, 2006; Resick, y Schnicke, 1993).

2. Desensibilización y reprocesamiento por movimientos oculares para el Trastorno por Estrés Postraumático (DMRO/EMDR; Shapiro, 2001). Esta terapia es una variante de la exposición en la imaginación pero a diferencia de la exposición se le pide al paciente que centre su atención en algún detalle inquietante del recuerdo y que se centre en cualquier cosa que aparezca durante una serie de movimientos oculares u otras formas de estimulación bilateral y pase un breve periodo de tiempo atenta al recuerdo perturbado. Shapiro y Silk Forest (2008) señalan que aunque aparezca inquietud, al finalizar la sesión los pacientes se muestran más tranquilos. Estos autores enfatizan que la eficacia de la DMRO en el tratamiento del TEPT se asemeja a la de la terapia de exposición prolongada sin necesidad de recurrir al empleo de entre 30 y 60 horas de trabajo adicional en casa.

3. Exposición prolongada para el Trastorno por Estrés Postraumático (Basada en alta evidencia empírica). Las víctimas tratan de evitar y olvidar la situación traumática. A veces el silencio y la distracción, justo con el paso del tiempo y el retomar las actividades cotidianas suelen ser estrategias útiles. Sin embargo, no siempre sucede así y si por el contrario se siguen experimentando síntomas de reexperimentación rabia o ira más allá de los primeros meses del hecho traumático por lo que se recomienda como terapia de primera elección la terapia de exposición. Exponerse a imágenes traumáticas bajo el control de un terapeuta ayuda a transformar las imágenes y sensaciones dolorosas mantenidos en la memoria emocional en sucesos ordenados espacial y temporalmente bajo el control de la memoria verbal (Echeburúa y Corral, 2008; pag 162)

La mayoría de estos estudios han aplicado el procedimiento de exposición en imaginación a las memorias traumáticas, ya que así lo imponen tanto razones éticas como aquellas derivadas de la naturaleza conceptual propia del trastorno (por ejemplo, la sintomatología postraumática desarrollada por una violación o desastre 
natural) (Báguena, 2001). El fundamento teórico de la terapia de exposición es que en un primer momento activa el miedo presente en los recuerdos traumáticos, para después permitir al paciente tener una experiencia correctora en ausencia de consecuencias aversivas.

En el tratamiento con adultos, la terapia de exposición es el tratamiento que cuenta con un mayor número de estudios controlados dirigidos a evaluar su eficacia. En general, la exposición a la memoria traumática se inicia en la sesión, y se pide a la paciente que escuche la grabación de su recuerdo traumático como tarea entre sesiones. El propósito de esta exposición en la imaginación es permitir que se procese completamente el suceso traumático, y enseñarle que 1) los recuerdos sobre el trauma no son peligrosos en sí mismos y no es lo mismo que reexperimentar el trauma de nuevo; 2) la ansiedad puede controlarse sin escapar o evitar los estímulos temidos; y 3) la ansiedad y los síntomas de TEPT se pueden experimentar sin perder el control. En general, las exposiciones jerárquicas en vivo (por ejemplo, en persona) también forman parte de la exposición prolongada, que implica confrontación con los recuerdos sobre el trauma, donde se incluye a la gente, los lugares, objetos, etc. La terapia por exposición prolongada dura aproximadamente 16 sesiones y se puede impartir dos veces por semana o semanalmente; se suele utilizar junto con otras técnicas cognitivo-conductuales (Foa, Hembree y Rothbaum, 2007). En el caso de niños y adolescentes puede que incluso aumente los síntomas durante las sesiones de exposición por lo que se recomienda una exposición gradual.

Foa y col. (2005) han estudiado la eficacia diferencial de la terapia de exposición aplicada en solitario y en combinación con reestructuración cognitiva en el tratamiento del TEPT. Participaron 179 víctimas de una agresión en la edad adulta o violación en la infancia, que fueron aleatoriamente asignadas a terapia de exposición $(\mathrm{N}=79)$, combinación de terapia de exposición y terapia cognitiva $(\mathrm{N}=74)$ o grupo control en lista de espera $(\mathrm{N}=26)$. El tratamiento fue aplicado en modalidad individual y tuvo una duración de nueve sesiones de periodicidad semanal. Aquellas mujeres que al final de la octava sesión no habían reducido en

un $70 \%$ su sintomatología postraumática recibieron entre una y tres sesiones más de tratamiento. Los resultados indican que tanto la exposición como la combinación de terapia de exposición y reestructuración cognitiva fueron superiores al grupo control en lista de espera en la reducción de la sintomatología de TEPT y sintomatología depresiva y en la mejora del funcionamiento social y laboral, sin que se encontraran diferencias entre ellas.

En resumen, un número suficiente de ensayos bien controlados aportan pruebas inequívocas de que la terapia de exposición es el tratamiento más eficaz para el TEPT (Foa al, Kean, Friedman y Cohen, 2009). Es, sin duda, la intervención que cuenta con una mayor evidencia empírica, tanto desde el punto de vista de la efectividad como desde el punto de vista de la eficiencia, en el tratamiento de este trastorno.

En cuanto a la intervención con niños y adolescentes los estudios de investigación muestran que la TCC es el método más eficaz para el tratamiento del trauma. Una de las terapias más investigadas es la terapia cognitivo conductual enfocada en el trauma TCC (TF-TCC) (Cohen, Mannarino y Deblinger, 2006). TF-TCC incluye la exposición (expone generalmente el evento traumático), técnicas de manejo de la ansiedad como la relajación y el entrenamiento asertivo, y la corrección de los pensamientos traumáticos inexactos o distorsionados. Aunque hay cierta controversia respecto a exponer a los niños a los eventos que les provocan miedo. Los tratamientos basados en la exposición-parecen ser relevantes cuando los recuerdos o los recuerdos del trauma causan un malestar significativo. Los niños pueden exponerse gradualmente y se les enseña la relajación para que puedan aprender a relajarse al tiempo que recuerdan sus experiencias. A través de este procedimiento, se enteran de que no tienen que temer de sus recuerdos. La TF-TCC también implica desafiar las creencias falsas de los niños, tales como, "el mundo es totalmente seguro." La mayoría de los estudios han encontrado que es seguro y eficaz usar la TCC para los niños con trastorno de estrés postraumático. La TF-TCC es a menudo acompañada de psicoeducación y participación de los padres. Psicoeducación es la educación sobre los síntomas de TEPT y sus efectos. Es tan importante para los padres y cuidadores comprender los efectos del trastorno de estrés postraumático como lo es para los niños (King, Tonge, Mullen, Myerson, Eyne, Rollings, Martin, y Ollendick, 2000). Esta técnica se puede aprender de forma gratuita y ha formado a más de 30,000 participantes (ver recursos en Internet). 


\section{Caso Clínico}

\section{Motivo de consulta}

Noemí a los 17 años acude a Urgencias del HCSC por un mareo y desvanecimiento. Se le diagnóstica una úlcera gástrica con dolor de larga evolución. Tras valoración por el servicio de digestivo es remitida a endocrinología por haber perdido aproximadamente unos $20 \mathrm{kgs}$ en los últimos meses en relación a una disminución de ingesta. La paciente niega tomar diuréticos/laxantes, así como provocarse vómitos y realizar actividad física. Es derivada a psiquiatría a la Unidad de Trastornos de la Conducta Alimentaria (UTCA) por posible Anorexia Nerviosa. Comunica al Psiquiatra de UTCA (año y medio después de ser atendida en urgencias) que desde hace 6 meses está en "huelga de hambre" para que sus padres la envíen a vivir con su abuela en su país de origen. En el momento de dicha exploración presenta ánimo bajo reactivo a conflictiva familiar. Refiere a su vez ideas pasivas de muerte sin ideación autolítica o planificación autolítica actual. Se la diagnostica episodio depresivo reactivo a situación actual; se descarta un TCA y se la deriva de modo preferente al CSM de su zona.

\section{Factores antecedentes}

\section{Antecedentes Biográficos}

Noemí vino a España a los 15 años por un procedimiento de reunificación familiar. La paciente informa que a ella le hubiera gustado quedarse a vivir en su país de origen, sin embargo "sus padres querían darle a ella y a sus hermanos un mundo mejor" por lo que no pudo negarse a venir. Desde que llegó a España sus padres no la dejan casi "salir" por temor a las drogas y al descontrol de esta sociedad. Aquí ha salido con un chico, pero dice que las cosas no fueron bien y lo dejaron, pero siguen siendo muy amigos. En cuanto a intereses y motivaciones muestra interés por la música y chatear con sus amigos por Internet. (Gráfico 2).

\section{Factores Precipitantes}

Manifiesta que cuando volvió a vivir en Madrid se volvió a encontrar con un familiar que en su país de origen en una ocasión había abusado sexualemente de ella. La paciente verbaliza que éste en un inicio se comportó adecuadamente y ella llegó a creer que había cambiado. Sin embargo, al cabo de un año y medio empezó a tocarla y acosarla sexualmente diciéndole que estaba "más buena" desde que había subido de peso y estaba "más gordita", por lo que informa que pensó en adelgazar para dejar de serle atractiva.

El acoso sexual meses antes de la última agresión provocó en la joven sintomatología somática (perdió el apetito, problemas de sueño, dolores musculares...). La paciente informa en la primera cita con su psiquiatra haber sufrido una violación el mes anterior por parte de un familiar. Se le diagnostica Trastorno por estrés postraumático (TEPT) y es atendida ese mismo día de modo urgente por parte de la psicóloga clínica del CSM que a su vez es la coordinadora de la Unidad de Trama Psíquico y Violencia del HCSC. (Gráfico 1)

Es atendida en el CSM a las 5 semanas de la derivación e informa en la primera cita con su psiquiatra haber sufrido 4 semanas antes una violación por parte de un familiar que representó una amenaza para su vida provocando una reacción emocional de temor intenso, desesperanza u horror. En la exploración psicológica se observan síntomas de reexperimentación (pesadillas, recuerdos intrusivos...), evitación e hiperactivación (problemas de sueño, estado de alerta, problemas de concentración e irritabilidad). Toda esta sintomatología se ha prolongado más de un mes y provocan en la paciente un malestar clínico significativo, un deterioro social, familiar y escolar como también en otras áreas importantes de su vida. 


\section{Instrumentos de evaluación}

En el protocolo de evaluación utilizado se incluyó la entrevista clínica y la aplicación de tres autoinformes. El objetivo de estos tres autoinformes fue contrastar la sintomatología observada durante la entrevista clínica (TEPT y Depresión) así como el grado de interferencia de las mismas en los distintos ámbitos de su funcionamiento cotidiano. Los instrumentos utilizados presentan una alta sensibilidad al cambio con el fin de poder verificar la eficacia del tratamiento aplicado una vez finalizado.

Escala de gravedad de síntomas del trastorno de estrés postraumático (EGS; Echeburúa, Corral, Amor, Zubizarreta y Sarasua, 1997)

Esta escala es una entrevista estructurada que sirve para evaluar la gravedad e intensidad de los síntomas del trastorno de estrés postraumático según los criterios del DSM-IV -TR (American Psychiatry Association, 2000) en víctimas de diferentes tipos de acontecimientos traumáticos. Consta de 17 ítems que corresponden a los síntomas del TEPT, más una escala complementaria de 13 ítems. La gravedad total de la sintomatología del trastorno se obtiene al sumar el nivel de frecuencia e intensidad de los síntomas (0-3) de cada síntoma. La gravedad de cada grupo de síntomas (reexperimentación, evitación y activación) se evalúa de la misma manera. La puntuación mínima requerida para el trastorno de estrés postraumático es de 12, con una distribución de dos puntos en la escala de reexperimentación -se requiere 1 síntoma-, de seis en la evitación -se requieren 3 síntomas- y de cuatro en la de activación -se requieren 2 síntomas-. El rango de la puntuación total del TEPT es de 0-51, el de la subescala de reexperimentación es de 0-12, el de evitación es de 021 y el de activación es de 0-18 (Echeburúa, 1997). Se evalúa la gravedad del trastorno mediante los puntos de corte de la escala global (15) y en la tres subescalas (5,6 y 4 respectivamente). Se suma también la puntuación obtenida en la escala complementaria con un rango de 0-39.Su índice de consistencia interna es de 0.92. La fiabilidad test-retest es de 0.89 y la validez convergente es alta y significativa. Y es sensible al cambio terapéutico.

\section{Escala de Inadaptación de Echeburúa (EI) (Echeburúa, Corral y Fernández-Montalvo, 2000)}

Se trata de una escala de evaluación autoaplicada que consta de seis ítems, que se valoran de 0 a 5 puntos en escala tipo Likert y mide el grado en el que el suceso traumático interfiere en la adaptación global del sujeto, así como en diferentes áreas específicas de la vida cotidiana: trabajo y/o estudios, relación social, tiempo libre, relación de pareja y relación familiar.

Las puntuaciones totales pueden oscilar entre 0 y 30, estableciéndose como puntos de corte la puntuación 12 en la escala total y la de 2 en cada uno de los ítems para discriminar los niveles clínicamente significativos de inadaptación. Las propiedades psicométricas son satisfactorias (Echeburúa et al., 2000).

Inventario de Depresión de Beck (BDI) (Beck, Rush, Shaw y Emery, 1979) (versión española de Vázquez y Sanz, 1998)

El BDI es uno de los instrumentos más empleados para avalar la depresión en sujetos adultos. En España existen dos adaptaciones (Conde, Esteban y Useros, 1976; Vázquez y Sanz, 1991). La primera se basa en la versión original y está compuesta de 19 ítems, debido a que se eliminaron el ítem relativo a sentimientos de castigo e imagen corporal; la segunda adaptación mantiene los 21 ítems consistentes en una serie de afirmacio- 
nes referidas a un síntoma particular de la depresión. Cada ítem consta de cuatro o cinco opciones de respuesta que se corresponden con distinta gravedad de expresión del síntoma. Se puntúa cada ítem de 0 a 3 . La puntuación global oscila entre 0 y 63 puntos. Las categorías de severidad se han dividido en intervalos: estado no depresivo (0-9 puntos), depresión media (10-15 puntos), depresión moderada (16-23 puntos) y depresión severa (24-63 puntos). Este instrumento da más importancia a los componentes cognitivos de la depresión que a los conductuales y somáticos.

El BDI posee unas buenas propiedades psicométricas, con una fiabilidad media de coeficiente alfa de 0,86 y 0,74, según Beck, Steer y Garbin (1988). El BDI presenta una fiabilidad alta en términos de consistencia interna (alfa total de la escala $=0,90$ ). Con un punto de corte de 21 , la sensibilidad es del $75 \%$ y la especificidad del 76\% (Richter, Werner, Heerlein, Graus y Saber, 1989; Weis, Griffin y Mirin, 1989; Vázquez y Sanz, 1999).

\section{Diagnóstico Clínico Multiaxial}

A raíz de la entrevista y de los resultados obtenidos en los instrumentos de evaluación se puede concluir que la paciente sufre de un TEPT crónico, presenta síntomas ansioso-depresivos moderados (especialmente en la esfera cognitiva). Muestra una cierta inadaptación a la vida cotidiana especialmente en el ámbito escolar y familiar. Las estrategias de afrontamiento utilizadas para superar el malestar emocional han sido "ponerse en huelga de hambre" y no salir de casa. Además la paciente recurre al consumo de alcohol, como manera de superar el malestar de forma puntual durante un mes.

- EJE I: TEPT, Episodio ansioso-depresivo moderado.

- EJE II: sin criterios.

- EJE III: úlcera gástrica, pérdida de peso.

- EJE IV: cambio de país de residencia, dificultades para adaptarse a otra cultura, inadaptación escolar, violación.

- EJE V: Eje de Evaluación de la actividad global (EEAG): 61

\section{Tratamiento}

\section{Motivación para el tratamiento}

La paciente decide comunicar sobre el incidente trumático al psiquiatra que la atiende por primera vez, explicando que "ya no puede más". Expresa que ya había callado por mucho tiempo la primera agresión sexual que había sufrido por este mismo familiar cuando tenía 14 años de edad en su país de origen. Expresa que si la volviera a agredir "llegaría a volverse loca". Dado que la paciente está experimentando un malestar general significativo verbaliza su deseo de recibir tratamiento. Tras establecer una buena relación terapéutica se establecen los objetivos terapéuticos. La jerarquía de los objetivos está en función de la protección y seguridad de la paciente. También según la urgencia de los síntomas, pero también de las expectativas y de las demandas de la paciente.

\section{Objetivos terapéuticos}

Existe evidencia de que las víctimas de violación se recuperan entre el primer y tercer mes después de la agresión sin tratamiento (Kilpatrick, Veronen y Resick, 1979). Sin embargo, el objetivo primordial -además de 
aumentar su seguridad- con esta víctima era evitar la cronificación del trastorno dado que presentaba como antecedente una agresión sexual previa, un factor considerado como predictor de cronificación del TEPT.

1. Se establece, en primer lugar, con la paciente el nivel de peligrosidad del agresor y la probabilidad de una futura agresión sexual (Villavicencio, 2001; Walker, 1994; Walker , 2009) y se elabora un plan de seguridad personal con relación al agresor y a las ideas de muerte. Intervención enfocada a la prevención de suicidio.

2. Aspectos médicos asociados a una violación (Médico de Atención Primaria). Durante la intervención en crisis a menudo se requiere que los servicios de salud coordinen su trabajo con otros profesionales de la red sanitaria, así como también con justicia, servicios de asesoramiento legal, servicios sociales para así proporcionar a las víctimas todos los servicios que necesitan en estas circunstancias. Por esa razón se envía una solicitud de pruebas protocolizadas tras una agresión sexual a su médico de atención primaria (MAP).

3. Seguimiento del plan de alimentación saludable propuesto por los Nutricionista del Hospital Clínico San Carlos quien la hace un seguimiento del peso y alimentación a lo largo de todo el tratamiento psicológico.

4. Se normaliza las reacciones postraumáticas. Reestructuración cognitiva de la interpretación que hace la víctima de sus síntomas y de los sentimientos de culpa, vergüenza, relacionados con la agresión (Corral, Echeburúa, Sarasua y Zubizarreta, 1995).

5. Al ser una paciente adolescente se incluye como objetivo sesiones psicoeducativas familiares donde se explica a los padres y hermanos las reacciones más comunes y acuerdo con respecto al plan de protección externa e interna (ideación autolítica).

6. Aprendizaje de estrategias de control de la ansiedad: relajación muscular progresiva y respiraciones diafragmáticas.

7. Recuperación de la sintomatología postraumática a través de técnicas de exposición: a) Exposición a estímulos evocadores de ansiedad y evitación en la vida cotidiana. b) Exposición gradual a actividades evitadas y gratificantes. c) Exposición en imaginación a las pesadillas e imágenes traumáticas intrusivas a través de la lectura repetida de las mismas en sesiones d) Exposición gradual a las conductas sexuales evitadas (objetivo al que se muestra motivada en la última sesión de tratamiento, pero decide aplazarlo hasta finalizar el procedimiento legal).

El programa de evaluación, tratamiento y seguimiento consta de 27 sesiones individuales (más de 20 debido a la situación de crisis en la que paciente estuvo inmersa tras denunciar los hechos y tener un conflicto con sus padres) y 8 sesiones grupales de aprendizaje y práctica de relajación muscular progresiva de Jacobson. Estas técnicas son una herramienta fundamental para hacer frente a la hiperactivación fisiológica. Se le explica la necesidad de realizar los ejercicios diariamente para conseguir el máximo de beneficio y poder utilizarlos frente a situaciones estresantes y ansiógenas.

En cuanto al tratamiento farmacológico la paciente informa haber tomado Cipralex (15)/ día pautado por la psiquiatra de la UTCA pero que lo suspendió a los pocos días por no acordarse de tomarla; manifiesta no querer medicación.

En primer lugar, se establece un plan de seguridad y protección con relación al riesgo de sufrir otra agresión por parte de un familiar dado que ya tenía antecedentes de haberla agredido con anterioridad y tener acceso casi permanente al domicilio de la paciente. La paciente manifiesta que la había amenazado de muerte si hablaba del suceso y que este mismo familiar tenía una denuncia, que se retiró por intermediación de la madre. Tras valorar el riesgo de mantener o no en el silencio la agresión, decide tomar la medida de no abrirle la puerta de casa cuando esté sola y la posibilidad de comunicarle lo sucedido a sus padres en la siguiente sesión (se envía una nota invitando a sus padres para que acudan a la siguiente cita con la paciente). En esa sesión, la paciente, junto con su terapeuta, valoraría la posibilidad de informarles sobre la agresión, o por lo menos expresar el miedo que le provocaba la agresividad y el consumo de drogas de su familiar. En la segunda sesión informa 
habérselo comunicado a su madre y que ella le creyó. Esa misma noche refiere haber pensado en quitarse la vida por todos los problemas que ha causado en la familia. Se realiza una reestructuración cognitiva ante el sentimiento de culpa, reasignación de responsabilidad al agresor y reevaluación de la idea autolítica. La paciente reflexiona sobre el poder que tendría el agresor si ella muere y decide no darle esa satisfacción. Se establece de un plan para la prevención del suicidio que incluye psicoeducación de las reacciones traumáticas y contrato terapéutico con la terapeuta y comunicación telefónica con su padre para reducir el riesgo externo e interno. Éste se muestra comprensivo y sensible a la situación de su hija.

De la segunda a la quinta sesión de psicoterapia individual se ponen en marcha medidas preventivas de contención y abordaje familiar del problema. La madre acude con la paciente a la tercera sesión, se realiza psicoeducación de las reacciones traumáticas y ésta comunica que toda la familia la apoya. Nota que su hija está mejor, que ahora habla más y que antes se callaba todo. Se vuelve a valorar la ideación autolítica.

En la cuarta sesión acude con su padre quien inicialmente recrimina a la paciente por no haber hablado antes, se realiza una sesión de psicoeducación sobre las reacciones traumáticas más comunes con el fin de que entienda las razones por las que las víctimas ocultan lo ocurrido, añadiendo el miedo al agresor por la amenaza y anterior agresión en su país de origen y se deriva a un centro de asesoramiento jurídico para valorar medidas judiciales disponibles.

La paciente decide denunciar tras recomendación de su MAP. Esta decisión causa una gran discusión familiar por lo que realiza un intento autolítico leve por el que es atendida en urgencias. Acuden su padre y madre al día siguiente de estos acontecimientos a la consulta que tenía establecida por la paciente con la psicóloga clínica encargada de su caso. Se realiza nuevamente una intervención psicoeducativa familiar con relación a la sintomatología traumática, en especial con respecto a la ideación suicida y al derecho que tienen las víctimas a denunciar sin contar con la aprobación de los demás, más aún cuando siguen una recomendación de un profesional sanitario. Se restablece nuevamente el pacto contra el suicidio con la paciente, mostrándose autocrítica con el gesto autolítico y expresa que no lo volvería a hacer porque ha visto que le haría mucho daño a su familia. Se recomienda a los padres estar atentos a los cambios emocionales de la paciente y acompañarla durante este proceso. Los padres muestran su apoyo y comprensión ante las reacciones de su hija, lo cual tienen un efecto positivo en la recuperación de la víctima.

En la sexta sesión la paciente acude a consulta y cuenta que la semana anterior había prestado declaración ante el juez donde tiene que relatar las agresiones sexuales sufridas como también a las profesionales del centro de asesoramiento jurídico. En esa sesión se muestra incapaz de poder hablar aquejándose de dolor de cabeza intenso. Es atendida por el psiquiatra de urgencias quien le administra un ansiolítico para bajar su estado de ansiedad. Se contacta con su hermana mayor quien la acompaña a su hogar y se la cita como preferente al día siguiente. Acude a la siguiente cita con su hermana. Comunica que ese fin de semana vio a la hermana del agresor (quien ha dejado de hablarle) y que los hermanos de su padre le habían dicho que el agresor amenazaba con matarla cuando volviese a su país de origen. Se realiza a su vez una sesión psicoeducativa con la hermana con relación a los síntomas postraumáticos y prevención frente a la ideación suicida.

Se la cita dos veces a la semana con el fin de seguir realizando la evaluación y una intervención en crisis ante los últimos acontecimientos. En la octava sesión informa sentirse mucho mejor escuchando música y leyendo poesía. A partir de la novena sesión se abordan las cogniciones resultantes del trauma y se reestructuran cognitivamente los puntos de estancamiento (Monson, Schnurr, Resick, Friedman, Young-Xu, y Stevens, 2006).

Los recuerdos traumáticos aparecen en forma de pesadillas recurrentes durante el sueño, por lo que la paciente acepta empezar una exposición prolongada a la pesadilla más reciente (relacionada con la última agresión). Se escribe la pesadilla y se le pide añadir un final más positivo. Se la explica que de esta forma se puede ejercer cierto control sobre los sueños. Se realiza la exposición prolongada ante esta pesadilla en sesión consiguiendo una reducción significativa del malestar. Además se le asigna como ejercicio para casa, leer diariamente la redacción de su sueño justo antes de dormir, concentrarse en ella hasta que disminuya el malestar. 
A partir de la undécima sesión la paciente informa haber hecho la exposición a la pesadilla todas las noches y que no piensa dejar de hacerlo porque gracias a ello ya no sigue teniendo pesadillas. A continuación se aborda el núcleo del trauma dado que manifiesta no estar acudiendo a su centro de estudios porque en clase cuando se despista le vienen imágenes intrusivas de la agresión. Acepta exponerse gradualmente a las imágenes temidas. En primer lugar se expone en el contexto protegido de la sesión a los estímulos cognitivos temidos (el aspecto físico y la voz del agresor, el lugar de la agresión, música que sonaba durante la agresión, color de la camiseta del agresor, etc) mediante la lectura en alto del relato escrito de las imágenes intrusivas, el cual solo termina cuando se reduce significativamente el grado de malestar. Se aplica imaginación guiada positiva como técnica de control emocional antes de empezar la exposición prolongada.

La paciente recibe las siguientes instrucciones de la terapeuta (Echeburúa y Corral, 2008; pg 170):

"Vas a cerrar los ojos para concentrarte mejor y a continuación vas a evocar los recuerdos traumáticos en voz alta. Intenta recordar los sucesos tan vívidamente como sea posible, con todas las imágenes, los sonidos, la temperatura y hasta los olores que estaban presentes. Cuéntamelo en primera persona y en presente, como si estuviera ocurriendo ahora mismo. No te preocupes si tienes ganas de gritar o de llorar: hazlo libremente. Mantén la atención hasta que disminuya el malestar. Esto te puede llevar un buen rato (45 o $60 \mathrm{~min}$ ) Me vas a contar con detalle lo que piensas y sientes. Si te encuentras muy incómoda porque te sientes irritada, avergonzada e incluso culpable y tienes la tentación de apartar esas imágenes de tu mente, no te preocupes; yo estoy contigo y te ayudaré a mantener la atención y a "dirigir" la experiencia. En ningún caso vas a perder el control o volverte loca. Vamos a poner por escrito tu narración para que puedas exponerte en casa como tarea. Cuando termines con este ejercicio en casa puedes sentirte cansada".

Se asigna como ejercicio para hacer en casa leer en alto (no tiene dispositivo de grabación para sólo escuchar el relato) diariamente el ejercicio de exposición hecho en la sesión y concentrarse en él hasta que disminuya el malestar. Se recomienda al terminarlo que en casa se imagine durante algunos minutos algunas escenas relajantes, o a dedicarse a alguna actividad placentera, como escuchar una canción agradable, salir a dar un paseo etc.

A mitad del tratamiento la paciente expresa que el agresor suele pasear por su barrio a pesar de que no vive en la zona; todo esto le ocasiona mucho malestar y una recaída en la sintomatología postraumática. Se retoma las medidas de protección y seguridad. La paciente informa tras estos acontecimientos que ha empezado a salir con un muy buen amigo y a beber alcohol para "olvidar". Se le explica los efectos perjudiciales del consumo de alcohol en la sintomatología postraumática y acepta interrumpir ese patrón de bebida, especialmente cuando está deprimida e irritable. Se subraya los efectos que el alcohol provoca en su seguridad personal y lo vulnerable que puede encontrarse ante una situación de peligrosidad. Gracias a que este tipo de conducta no ha sido hasta ese momento un problema en la paciente, acepta comprometerse a no beber. En las siguientes sesiones la paciente comunica no haber vuelto a tener tentaciones. A esto se suma que su pariente ha dejado de aparecer por su zona, y que su madre ha estado muy cercana y cariñosa con ella.

A partir de la vigésima sesión a efectos de completar tal tarea de exposición cognitiva la paciente debe enfrentarse gradualmente (exposición en vivo) a las situaciones externas evitadas (instituto, actividades lúdicas, etc.) así como relacionarse brevemente con otras personas en su entorno natural (actividades culturales organizadas por su centro de estudios, etc) siempre teniendo en cuenta su seguridad.

Tras las sesiones de exposición la paciente sólo permanece con un ligero malestar relacionado con salir sola de noche y por las zonas por las que su familiar frecuenta y verbaliza "Ya no tengo esos pensamientos de quitarme la vida porque me he dado cuenta que la vida es bella y merece vivirla." Se debe añadir que su madre le escribió una carta tras la intervención familiar, después del intento autolítico, donde le ponía lo mucho que la quería y que sin ella jamás la familia estaría completa. Esto hizo a la paciente sentirse querida y descartar completamente esa idea.

Las últimas sesiones se centran en la alimentación y consolidación de la mejoría, acostumbrando a la paciente a gratificarse por sí misma por los logros conseguidos. Finalmente, la paciente informa que "está tonteando 
con un amigo del instituto". Manifiesta su interés por tratar su miedo a mantener relaciones sexuales consentidas pero decide aplazar ese objetivo de tratamiento hasta que acabe finalmente el proceso judicial contra su agresor. Se continúa valorando la peligrosidad externa e interna, y se acuerda continuar el seguimiento del tratamiento hasta finalizar el segundo año.

\section{Resultados}

Al cabo de 27 sesiones (12 meses) cuando se ha concluido con la terapia, se realiza una nueva evaluación postratamiento a la paciente (Tabla 1). A raíz de los resultados obtenidos se puede concluir que la paciente ha superado el trastorno por estrés postraumático, presenta un ánimo positivo, un mejor funcionamiento y calidad de vida. Un dato significativo es la desaparición total de los síntomas de reexperimentación. En el postratamiento se observa cierta sintomatología de evitación y de hiperactivación, por debajo del punto de corte, sin embargo, es de preveer que a lo largo del proceso judicial la víctima tenga alguna recaída. Este es un riesgo que se ha de tener en cuenta aún después de la remisión completa de los síntomas (Echeburúa y Corral, 2008) por lo que se recomienda un seguimiento a este tipo de pacientes, en especial de aquellas cuyos procedimientos judiciales sean de larga duración y en los que el agresor es miembro de la misma familia (nuclear o extensa).

\section{Conclusiones}

Las secuelas físicas y psicológicas de los abusos y otros eventos traumáticos aumentan la probabilidad de que las víctimas entren en contacto con un centro de salud que los que no han sufrido eventos traumáticos. No obstante, debemos aclarar que, generalmente el motivo de la consulta es por problemas médicos y psicosomáticos relacionados directa o indirectamente con su situación traumática. Por esta razón, es fundamental que se sepa detectar adecuadamente las reacciones traumáticas y ofertar un programa especializado en trauma con un equipo interdisciplinar con una formación en psicotraumatología especializada (www.childtraumanetwork.com), con el fin de evitar una situación de abusos prolongados y por ende una cronificación y gravedad de los síntomas postraumático. La paciente es atendida en la Unidad de Trauma Psíquico y Violencia del Hospital Clínico San Carlos de Madrid. Este centro hospitalario a través de la Comisión contra la Violencia ha elaborado protocolos de actuación contra el maltrato al anciano, a la mujer y al niño. Esta Unidad se encuadra dentro del marco de actuación propuesto por la Subdirección General de Atención Especializada del Servicio Madrileño de Salud con el objetivo de establecer una pauta de actuación normalizada para los profesionales de los Centros Sanitarios, que posibilite una atención integral a las personas que sufren o han sufrido violencia. Se tiene programado en un futuro muy cercano ofrecer una intervención especializada a todas las víctimas de agresiones sexuales recientes que acudan a Urgencias de dicho centro hospitalario.

En cuanto a la intervención es de gran importancia contar con la participación activa de la víctima tanto en el desarrollo del plan de seguridad interno y externo como en el establecimiento de los objetivos terapéuticos como en la elección de las técnicas de intervención. Hay que reconocer que la víctima de agresiones sexuales cometidos por un familiar conoce muy bien al agresor y que es ella la que debe vivir con sus decisiones. No se debe tomar decisiones por ellas, debemos ayudarlas a evaluar sus alternativas y las consecuencias de sus decisiones (Walker, 1994). Es fundamental tener programas de atención especializada para víctimas de agresiones sexuales en centros de salud públicos, y que mantengan una buena coordinación con el resto de especialistas e instituciones que estén a cargo de la atención de las víctimas. 
Tabla 1. Resultados de los Instrumentos de evaluación en el pretest, mitad del tratamiento y postest

\begin{tabular}{|c|c|c|c|}
\hline \multicolumn{4}{|c|}{ INSTRUMENTOS DE EVALUACIÓN } \\
\hline & PRETEST & MITAD TRATAMIENT & POSTEST \\
\hline ESCALA DE GRAVEDAD DE SÍNTOMAS DEL TEPT (EGS). PC: 15 & 30 & 24 & 5 \\
\hline ESCALA DE INADAPTACIÓN (EI) & 22 & 13 & 5 \\
\hline INVENTARIO DE DEPRESIÓN DE BECK (BDI) & 26 & 24 & 8 \\
\hline \multicolumn{4}{|c|}{ ESCALA DE GRAVEDAD DE SÍNTOMAS DEL TEPT } \\
\hline Reexperimentación PC: 5 & 9 & 6 & 0 \\
\hline Evitación PC: 6 & 12 & 10 & 2 \\
\hline Activación PC: 4 & 9 & 8 & 3 \\
\hline
\end{tabular}

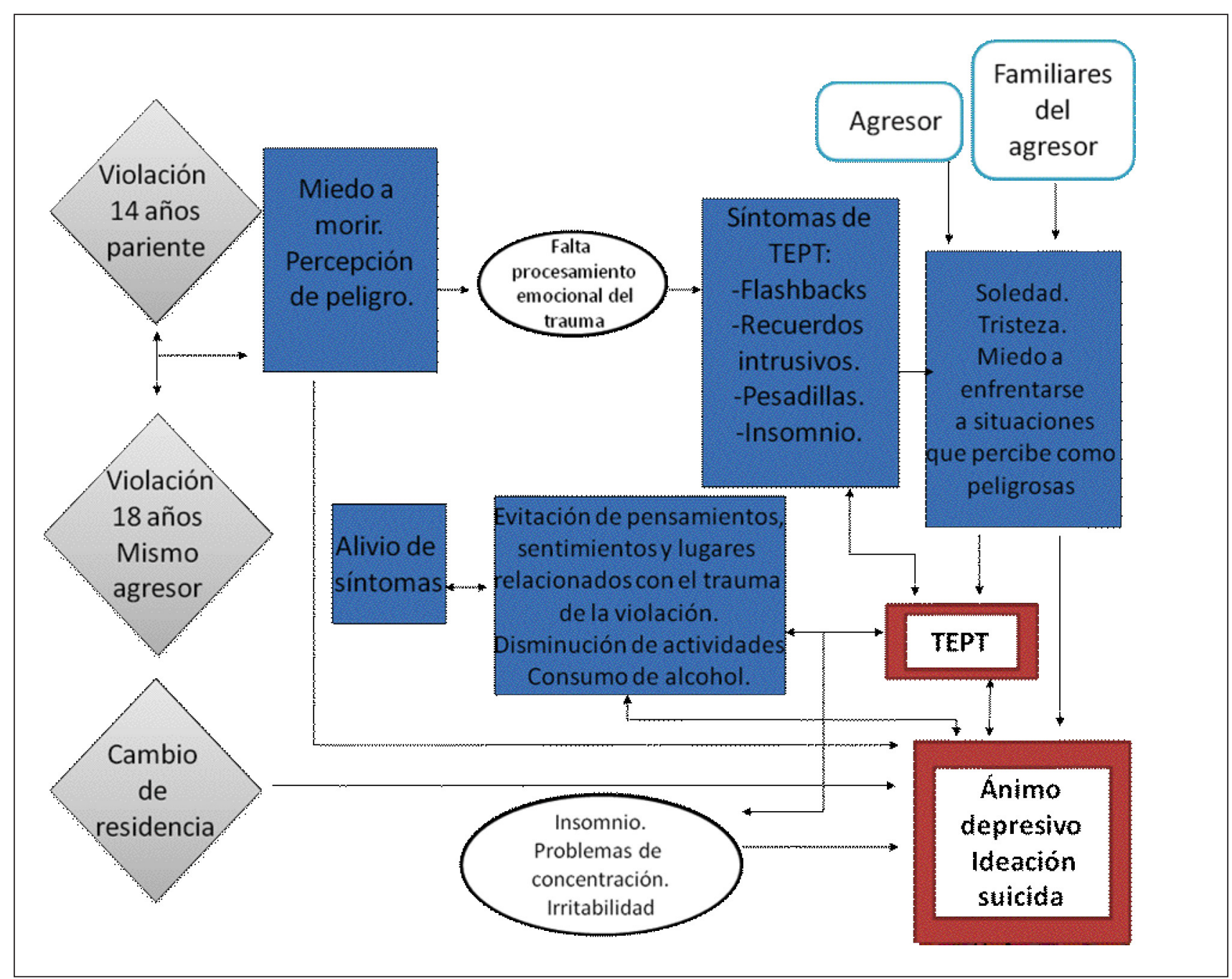




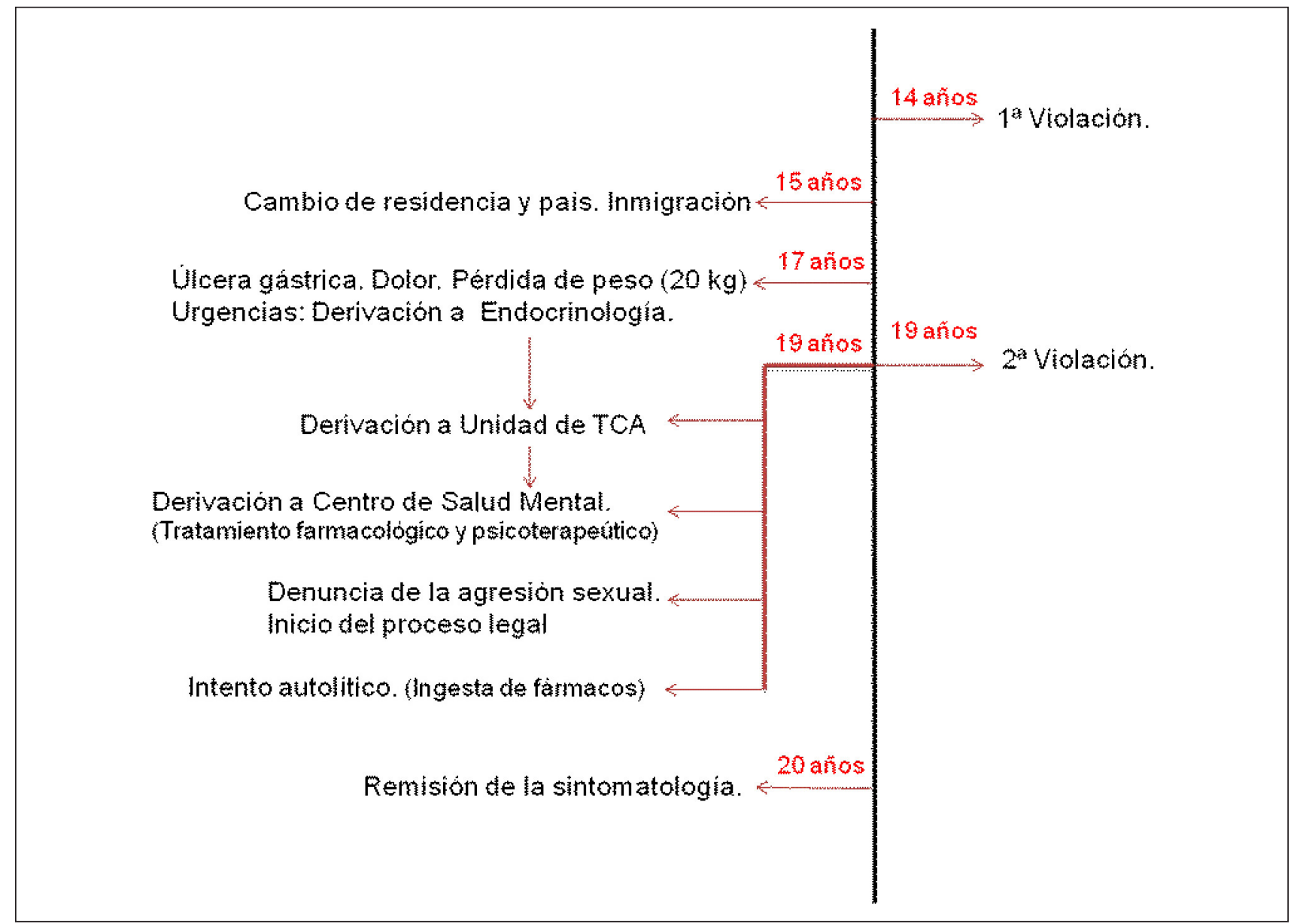

\section{Referencias}

American Psychiatric Association (2000). Diagnostic and statistical manual for mental disorders, DSM-IV-TR (4 ${ }^{\mathrm{a}}$. Ed. Texto revisado). Washington, DC: Author.

Amor, P. J., Echeburúa, E., Corral, P., Zubizarreta, I. y Sarasua, B. (2001). Perfil psicopatológico diferencial en víctimas de maltrato doméstico y de agresiones sexuales. Análisis y Modificación de Conducta, 27, 605-629.

Baguena, M. J. (2001). Tratamientos psicológicos eficaces para el estrés postraumático. Psicothema, 13, 479-492. Beck, A. T., Rush, A. J., Shaw, B. F., \& Emery, G. (1979). Cognitive therapy of depression. New York: Guilford. Beck, A. T., Steer, R. A. y Garbin, M. G. (1988). Psychometrics properties of the Beck's depression inventory. Twenty five years of evaluation. Clinical Psychology Review, 8, 77-100.

Bisson, J. I. y Cohen, J.A. (2006) Disseminating Early Interventions Following Trauma. Journal of Traumatic Stress, 19, 583-595.

Brewin CR, Andrews B, Valentine JD. (2000). Meta-analysis of risk factors for posttraumatic stress disorder in trauma-exposed adults. Journal of Consulting Clinical Psychology 68, 748-66.

Cloitre, M. (2009) Effective psycotherapies for PTSD: a review and critic. CNS Spectrums 14, 32-43.

Cohen, J. A., Berliner, L., \& March, J. S. (2000). Treatment of children and adolescents. In E. B. Foa, T. M. Keane, \& M. J. Friedman, (Eds.), Effective treatments for PTSD: Practice guidelines from the International Society for Traumatic Stress Studies. New York: Guilford Press.

Cohen, J.A., Mannarino, A.P., y Deblinger, E. (2006). Treating Trauma and traumatic grief in children and adolescents. New York: Guilford Press. 
Conde, V., Esteban, T., Useros, E. (1976). Revisión crítica de la adaptación castellana del cuestionario de Beck. Revista Psicología General Aplicada, 31, 469-497

Darves-Bornoz, J. M., Alonso, J., de Girolamo, G., de Graaf, R., Haro, J. M., Kovess-Masfety, V., ... Gasquet, I. (2008). Main traumatic events in Europe: PTSD in the European study of the epidemiology of mental disorders survey. Journal of Traumatic Stress. 21, 455-462.

Echeburúa, E., De Corral, P., Zubizarreta, I. y Sarasua, B. (1995). Trastorno de Estrés Postraumático crónico en víctimas de agresiones sexuales. A Coruña: Fundación Paidea.

Echeburúa, E., Corral, P., Sarasua, B., y Zubizarreta, I. (1996). Tratamiento cognitivo-conductual del trastorno de estrés postraumático en víctimas de maltrato doméstico: un estudio piloto. Análisis y Modificación de Conducta, 22, 627-654.

Echeburúa, E. y De Corral, P. (1997). Avances en el tratamiento cognitivo-conductual del trastorno de Estrés Postraumático. Ansiedad y Estrés, 3, 249-264.

Echeburúa, E., Corral, P., Amor, P. J., Zubizarreta, I. y Sasua, B. (1997). Escala de gravedad de síntomas del Trastorno por estrés postraumático: Propiedades psicométricas. Análisis y Modificación de Conducta, 23, 503-526.

Echeburúa, E., Corral, P. y Fernández-Montalvo, J. (2000). Escala de inadaptación (EI): Propiedades psicométricas en contextos clínicos. Análisis y Modificación de Conducta, 26, 325-340.

Echeburúa, E. (2004). Superar un Trauma: El tratamiento de las víctimas de sucesos violentos. Madrid: Pirámide.

Echeburúa, E. y Corral, P. (2008). Tratamiento psicológico del trastorno de estrés postraumático en una víctima de terrorismo. En J. P. Espada, J. Olivares y F. X. Méndez, (Eds.), Terapia Psicológica: Casos Prácticos (pp. 159-178). Madrid: Pirámide.

Figley (1978). Stress disorders among Vietnam Veterans: Theory, Research, and Treatment. In the Psychosocial Stress Book Series. New York: Brunner/Mazel.

Foa, E.B., Rothbaum, B.O., Riggs, D. y Murdock, T. (1991). Treatment of post-traumatic stress disorder in rape victims: A comparison between cognitive-behavioral procedures and counseling. Journal of Consulting and Clinical Psychology, 59, 715-723.

Foa, E. B., Dancu, C. V., Hembree, E. A., Jaycox, L. H., Meadows, E. A., y Street, G. P. (1999). A comparison of exposure therapy, stress inoculation training, and their combination for reducing posttraumatic stress disorder in female assault victims. Journal of Consulting and Clinical Psychology, 67, 194-200.

Foa, E. B., Keane, T.M., Friedman, M. J y Cohen, J. A. (2009). Effective Treatments for PTSD: Practice guidelines from the International Society for Traumatic Stress Studies. Second edition. New York: The Guilford Press.

Foa, E. B., Hembree, E. A., Cahill, S. P., Rauch, S. A. M., Riggs, D. S., Feeny, N. C. (2005). Randomized trial of prolonged exposure for posttraumatic stress disorder with and without cognitive restructuring: Outcome at academic and community clinics. Journal of Consulting and Clinical Psychology, 73, 953-964.

Foa, E., Hembree, E., y Rothbaum, B. (2007). Prolonged Exposure Therapy for PTSD: Emotional Processing of Traumatic Experiences Therapist Guide. New York: Oxford University Press.

Foy, D., Madvig, B., Pynoos, R., y Camilleri, A. (1994). Etiologic factors in the development of posttrau- matic stress disorder in children and adolescents. Journal of School Psychology, 34, 133-145.

Frueh, B.C., Grubaugh, A.L., Cusack, K.J. y Elhai, J.D. (2009) Disseminating Evidence-Based Practices for Adults With PTSD and Severe Mental Illness in Public-Sector Mental Health Agencies. Behavior Modification. 33, 66-81

Herman, J. L. (2004). Trauma y recuperación. Espasa Calpe.

Kelley L. P., Weathers F. W., McDevitt-Murphy M. E., Eakin, D. E. y Flood AM. (2009) A Comparison of PTSD Symptom Patterns in Three Types of Civilian Trauma. Journal of Traumatic Stress, 22, 227-235

Kessler, R. C., Sonnega, A., Bromet, E., Hughes, M. y Nelson, C. B. (1995). Posttraumatic stress disorder in 
the National Comorbidity Survey. Archives of General Psychiatry, 52, 1048-1060.

King, N. J., Tonge, B. J., Mullen, P., Myerson, N., Heyne, D., Rollings, S., et al. (2000). Treating sexually abused children with posttraumatic stress symptoms: A randomized clinical trial. Journal of the American Academy of Child and Adolescent Psychiatry, 39, 1347-1355.

Monson, C. M., Schnurr, P. P., Resick, P. A., Friedman, M. J., Young-Xu, Y. y Stevens, S. P. (2006). Cognitive Processing Therapy for Veterans With Military-Related Posttraumatic Stress Disorder. Journal of Consulting and Clinical Psychology, 74, 898-907.

Morrison, A.P., Frame, L. y Larkin, W. (2003). Relationship between trauma and psychosis: a review and integration. British Journal of Clinical Psychology, 42, 331-353

Naciones Unidas (2006). Estudio a fondo sobre todas las formas de violencia contra la mujer Informe del Secretario General. A/61/122/Add.1

Organización Mundial para la Salud (OMS, 2002). Informe Mundial sobre la Violencia y la salud. Publicado en español por la Organización Panamericana de la Salud para la Organización Mundial de la Salud Washington, D.C.

Resick, P. A. y Schnicke, M. K. (1993). Cognitive processing therapy for rape victims: A treatment manual. Newbury Park, CA: Sage.

Richter, P., Werner, J., Heerlein, A., Jraus, A. y Sauer, H. (1989). On the validity of the Beck Depression Inventory. A review. Psichopathology, 3, 160-168.

Sanz, J. y Vázquez, C. (1998). El Inventario para la Depresión de Beck (BDI) como instrumento para identificar sujetos deprimidos y no deprimidos en la investigación psicopatológica: Fiabilidad, validez y datos normativos en muestras universitarias. Psicothema, 10, 303-318.

Shapiro, F. (2001). Eye Movement Desensitization and Reprocessing: Basic Principles, Protocols and Procedures (2nd ed.). New York: Guilford Press.

Shapiro, F. y Silk Forrest, M (2008). EMDR: una terapia revolucionaria para superar la ansiedad, el estrés y los traumas. Barcelona: Kairós S.A.

Silverman, W. K., Ortiz, C. D., Viswesvaran, C., Burns, B. J., Kolko, D. J., Putnam, F. W. y Amaya-Jackson, L. (2008). Evidence-based psychosocial treatments for children and adolescents exposed to traumatic events. Journal of Clinical Child \& Adolescent Psychology, 37, 156-183.

Valiente, C., Villavicencio, P., y Cantero, D. (2006). La fenomenología de la comorbilidad del trauma y la psicosis. Apuntes de Psicología Colegio Oficial de Psicología, 24, (1-3), 111-135.

Van der Kolk, B. A., Roth, S., Pelcovitz, D., Sunday, S., and Spinazzola, J. (2005). Disorders of Extreme Stress: The Empirical Foundation of a Complex Adaptation to Trauma. Journal of Traumatic Stress, 18, 389399.

Vázquez, C., Sanz, J. (1991). Fiabilidad y validez factorial de la versión española del inventario de depresión de Beck. Barcelona: III Congreso de Evaluación Psicológica. Citado por: M. I Comeche, M. I Diaz, M. A Vallejo. (1995). Cuestionarios, inventarios, escalas. Ansiedad, depresión y habilidades sociales. 186-190. Madrid: Fundación Universidad-Empresa.

Vázquez, C. y Sanz, J. (1999). Fiabilidad y validez de la versión española del Inventario para la Depresión de Beck de 1978 en pacientes con trastornos psicológicos. Clínica y Salud, 10, 59-81.

Villavicencio, P. (2001). Barreras que impiden la ruptura de una situación de maltrato. En R. Osborne (Coord.), La violencia contra las mujeres: Realidad social y políticas públicas (pp. 32-52). Madrid: UNED.

Villavicencio, P., Bustelo, M. y Valiente, C. (2007). Domestic Violence in Spain. En N. A. Jackson. (Ed): Encyclopedia of Domestic Violence. London: Routledge Editors.

Walker, L. E. A. (1994). Abused women and survivor therapy: A practical for the psychitherapist. American Psychological Association. New York: Springer.

Walker, L. E. A. with Research Associates (2009). The Battered Woman Syndrome Third Edition. New York: Springer. 
Weis, R. D., Griffin, M. L. y Mirin, S. M. (1989). Diagnosing major depression in cocaine abusers: The use of depression rating scales. Psychiatry Research, 3, 335-343.

Recursos en Internet

http://tfcbt.musc.edu/

http:// www.childtraumanetwork.com

Manuscrito recibido: 28/12/2010

Revisión recibida: 18/01/2011

Manuscrito aceptado: 19/01/2011 